\title{
Study of Depression, Anxiety, Stress, Suicide Risk and Resilience in Undergraduate Medical Students
}

\author{
Gaurav Verma ${ }^{1}$ \\ ${ }^{1}$ Assistant Professor of Psychiatry, Varun Arjun Medical College Banthra, Shahjahanpur, U.P.
}

\section{Abstract}

Background: To assess depression, anxiety, stress, suicide risk and resilience in undergraduate MBBS 1st Professional medical student. Subjects and Methods: 48 first professional MBBS students were participated in study before educational intervention. DASS, Suicidal behaviour questionnaire-Revised (SBQ-R), Connor Davidson's resilience scale were used. Results: Results showing that $43.75 \%$ having moderate depression, $25 \%$ have moderate anxiety and stress. 29.16\% students have SBQ-R $\geq 7$ (considered at risk of suicide). Depression has positive correlation with stress, anxiety and suicide. No significant correlation was found between resilience and depression, anxiety, stress and suicide risk. Conclusion: We need more such studies to assess mental wellbeing of medical students and appropriate measures to tackle the threat of suicide of future healer.

Keywords: Depression, Anxiety, Stress, Resilience.

Corresponding Author: Dr. Gaurav Verma, Assistant Professor of Psychiatry, Varun Arjun Medical College Banthra, Shahjahanpur, U.P

Received: December 2019

Accepted: December 2019

\section{Introduction}

As we all know, getting a medical degree in India is not an easy task. Students have to pass from stressful situations not only in under-graduation but also in speciality courses. Some students have been committed suicide due to unwearable stress and depression. Studies has been done to evaluate the ongoing stress and its effect on performance. ${ }^{[1]}$ We not only need more such studies but also action plan to minimise stress in students so that future healer can heal their patients in a better way.

\section{Objective and aim}

1. To study stress, anxiety, suicidal ideation, in undergraduate MBBS 1st Professional medical students.

2. Educate them about coping strategy for stress, anxiety and identify persons at risk of suicide.

\section{Subjects and Methods}

Forty eight MBBS first professional students were asked to participate in study. DASS, SBQ-R, Connor Davidson's resilience scale were used to assess depression, anxiety, stress, suicidal ideation and resilience respectively before educational intervention.

\section{Connor Davidson's Resilience Scale: ${ }^{[2]}$}

Conner-Davidson Scale consist of 25 items to measure resilience. It is five point likert scale that ranged from 0-4. The reliability and validity of scale is verified.

\section{Depression Anxiety Stress Scale (DASS): ${ }^{[3,4]}$}

Depression Anxiety Stress Scales is made up of 42 selfreport items to be completed over five to ten minutes, each reflecting a negative emotional symptom. ${ }^{[5]}$ Each of these is rated on a four-point likert scale of frequency or severity of the participants' experiences over the last week. These scores ranged from 0 , meaning that the client believed the item "did not apply to them at all", to 3 meaning that the client considered the item to "apply to them very much, or most of the time". It is also stressed in the instructions that there are no right or wrong answers.

Suicidal Behaviour Questionnaire-Revised (SBQ-R): SBQ-R has 4 items, each tapping a different dimension of suicidality. Response can be used to identify at risk individuals and specific risk behaviours. It has cut off score $\geq 7$ in adult general population. ${ }^{[6]}$

Analysis:

Analysis was done by using SPSS version 17.

\section{Results}

Table 1:

\begin{tabular}{|l|l|l|l|}
\hline Rating & Depression & Anxiety & Stress \\
\hline Moderate & $21(43.75 \%)$ & $12(25 \%)$ & $12(25 \%)$ \\
\hline Severe & $5(10.41 \%)$ & $15(31.25 \%)$ & $4(8.33 \%)$ \\
\hline $\begin{array}{l}\text { Extremely } \\
\text { severe }\end{array}$ & $1(2 \%)$ & $8(16.66 \%)$ & - \\
\hline
\end{tabular}

Total 48 undergraduate students participated in study in which 15 were female $(31.3 \%)$ and 33 male $(68.8 \%)$. One male student did not fill suicide questionnaire. 14( $29.16 \%$ ) 
students has SBQ-R score $\geq 7$ i.e considered at risk of suicide. $43.75 \%$ students fall in moderate category of depression, $16.66 \%$ fall under extremely severe anxiety [Table 1]. Mean score of resilience and others are as per [Table 2]. Correlation analysis [Table 3] shows that depression has positive correlation with anxiety $(\mathrm{p}<.05$, pearson correlation 0.741), stress $(\mathrm{P}<.05$, Pearson correlation 0.792) \& stress suicide $(\mathrm{p}<.05$, pearson correlation .402). There is not significant correlation of resilience with DAS and suicide risk.

Table 2:

\begin{tabular}{|l|l|l|l|}
\hline Rating & Mean & Std. deviation & N \\
\hline Resilience & 60.70 & 15.45 & 48 \\
\hline Depression & 12.43 & 7.00 & 48 \\
\hline Anxiety & 12.93 & 7.27 & 48 \\
\hline Stress & 15.79 & 7.16 & 48 \\
\hline Suicide & 5.17 & 2.72 & 47 \\
\hline
\end{tabular}

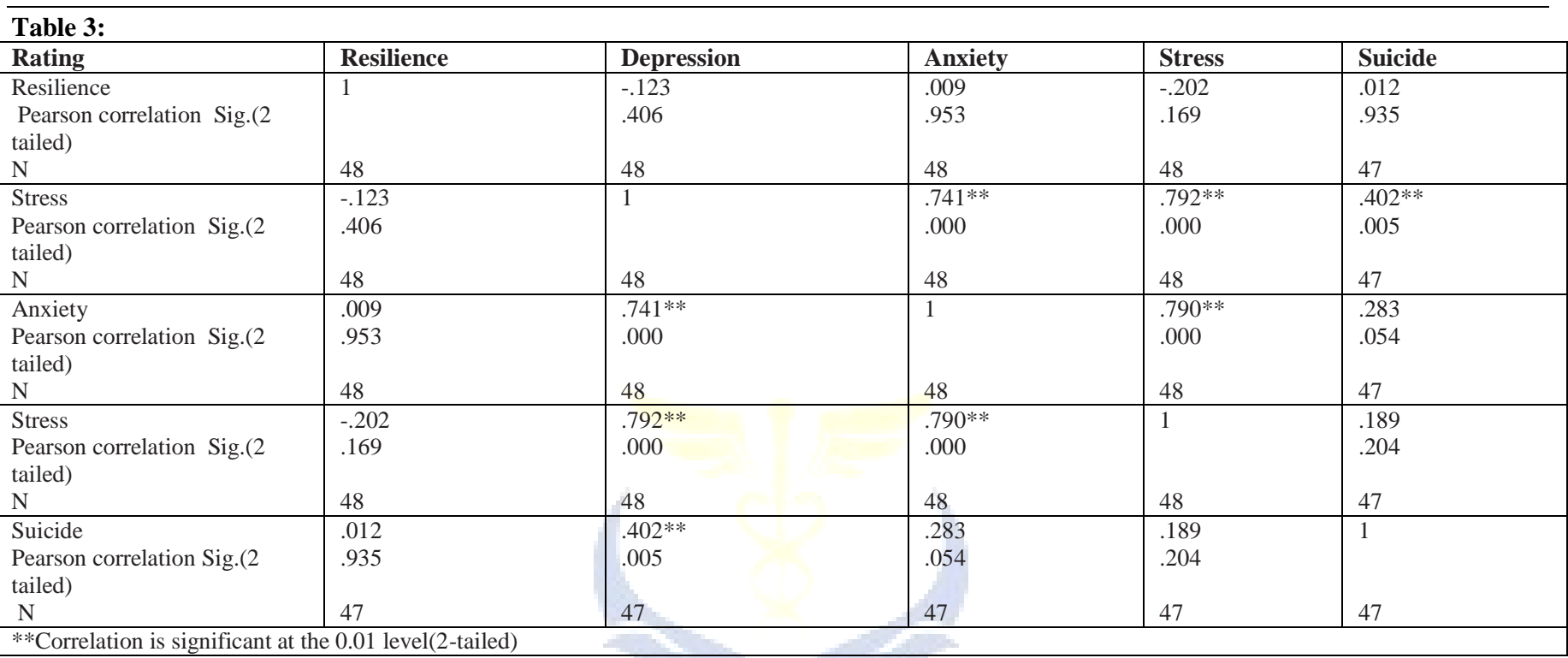

\section{Discussion}

As we all know that getting a medical degree in India is not an easy task. It required dedication and hard work. Most medical colleges are overburden due to patient load which affect the mental wellbeing of medical students due to excessive stress and long working hours. Now a days we heard increasing suicide rates in medical students due to many contributing factors needed to be evaluate. At global level about one million people commit suicide every year, a global mortality rate 16 per 10000 , or one suicide death every 40 second. ${ }^{[4]}$ But there are not much studies which shows suicide in medical students. Study has done to assess suicidal ideation in Indian medical students showing that suicidal ideation among medical students were $53.6 \%{ }^{[5]}$ Many factors seems to be contributing for suicidal risk including socioeconomic status, depression, stress etc. ${ }^{[5]}$ Which warrents further studies and favourable action to prevent such grave loss specially when our country is facing shortage of doctors. This study aimed to identify prevalence of depression, anxiety, stress and suicidal risk with resilience in first year undergraduate medical students. Medical students has to go many stressful situation making them vulnerable to depression and anxiety and suicide. A meta-analysis demonstrated that first year students has highest rate of depression and rate of depression, then gradually decreased at final year. ${ }^{[7]}$ This study shows that there is no correlation of resilience with depression, stress, anxiety and suicide risk. This may be due low sample size which may increased in further studies. So addressing mental wellbeing from root might make future doctors to be more stress free so can deliver better health services.

\section{Conclusion}

This study find that depression, stress, anxiety and suicidal risk are significant in medical students. There is no any significant correlation of above factors with resilience.

\section{Limitation of Study:}

Less sample population is major limitation of study.

\section{Acknowledgement}

To students who participated in study.

\section{References}

1. Rotelstein L ,Mamos M,Torre M et al. Prevalence of Depression, Depressive Symptoms, and Suicidal Ideation Among Medical Students: A Systematic Review and Meta-Analysis.JAMA. 2016 December 06; 316(21): 2214-2236. doi:10.1001/jama.2016.17324.

2. Connor KM, Davidson JRT (2003) Development of a new resilience scale: the Connor-Davidson Resilience Scale (CD-RISC). Depress Anxiety 18:76-82. https ://doi.org/10.1002/da.10113

3. Lovibond, S.H. \& Lovibond, P.F. (1995). Manual for the Depression Anxiety \& Stress Scales. (2 Ed.)Sydney: Psychology Foundation

4. WHO,Mental Health: Suicide Prevention(SUPRE).[ Accessed on 15 
sep 2010] available from; http//www.who.int/mental health/preventiom/suicide/suicide prevent/en/.

5. Goyal A, Kishore J, Anand T, Rathi A.Suicidal ideation among medical students. Journal of mental health and human behaviour. 2012;17(1).

6. Osman, A, Bagge, CL, Gutierrez, PM, Konick, LC, et al. FX
(December 2001). The Suicidal Behaviors Questionnaire-Revised (SBQ-R): validation with clinical and nonclinical samples. Assessment. 8 (4): 443-54. doi:10.1177/107319110100800409

7. R.Puthran, M.B. Zhang, W.W Tam, R.C Ho.Prevalence of depression amongst medical students: A meta-analysis.Medical education, vol.50,no 4,pp.456-468,2016.

Copyright: () the author(s), 2019. It is an open-access article distributed under the terms of the Creative Commons Attribution License (CC BY 4.0), which permits authors to retain ownership of the copyright for their content, and allow anyone to download, reuse, reprint, modify, distribute and/or copy the content as long as the original authors and source are cited.

How to cite this article: Verma G. Study of Depression, Anxiety, Stress, Suicide Risk and Resilience in Undergraduate Medical Students. Asian J. Med. Res. 2019;8(4):PY01-PY03.

DOI: dx.doi.org/10.21276/ajmr.2019.8.4.PY1

Source of Support: Nil, Conflict of Interest: Nil. 